\title{
Hyperventilation in the awake state: potentially treatable component of Rett syndrome
}

\author{
D P SOUTHALL,${ }^{*}$ A M KERR, $\dagger \mathrm{E}$ TIROSH, $\ddagger \mathrm{P}$ AMOS, $\S \mathrm{M}$ H LANG, ${ }^{*}$ \\ AND J B P STEPHENSON†
}

${ }^{*}$ Cardiothoracic Institute, Brompton Hospital, London, †Fraser of Allander Unit, Royal Hospital for Sick Children, Glasgow, $¥$ Hannah Khoushi Child Development Centre, Haifa City Medical Centre, Haifa, Israel, and §Epilepsy Centre, Quarrier's Homes, Bridge of Weir, Scotland

SUMMARY Hyperventilation, which occurs in some patients with severe mental handicap, is a prominent feature in the histories of most girls with Rett syndrome but its mechanism and effects have not been established. Respiratory function was therefore studied in 18 patients with Rett syndrome and 23 healthy controls. Ten of the patients $(56 \%)$, but none of the controls, hyperventilated only when awake, and began doing so after a period of normal breathing without hypoxaemia. After hyperventilation was established it was interspersed with prolonged periods of apnoea (over 19 seconds) accompanied by Valsalva manoeuvres. Hypoxaemia $(<90 \%)$ occurred in $47 \%$ of these periods of apnoea and five $(50 \%)$ of the patients had oxygen saturation values of under $50 \%$. During hyperventilation severe hypocapnia developed in every patient, and recorded arterial $\mathrm{pH}$ measurements ranged from $7 \cdot 47$ to $7 \cdot 60$. A further four patients $(22 \%)$ did not hyperventilate, but had clear histories of hyperventilation when younger. All had frequent apnoeic pauses accompanied by Valsalva manoeuvres. The remaining four girls $(22 \%)$ neither hyperventilated nor gave a clear history of doing so. Three had occasional apnoeic pauses associated with the Valsalva manoeuvres. All but one of the 18 patients had increased quantities of periodic apnoea compared with the control subjects.

The hypocapnic alkalaemia and hypoxaemia resulting from hyperventilation may contribute to the cerebral impairment in Rett syndrome. Since the hyperventilation is 'primary', and not secondary to preceding apnoea, it is potentially treatable. Further studies will determine if treatment is practical and of benefit.

Rett syndrome is a comparatively common cause of severe mental and physical handicap. The syndrome was first described in $1966,{ }^{1}$ and only affects girls, the estimated prevalence is $0 \cdot 8 / 10000$ girls up to the age of 14 years. $^{2} 3$

Hyperventilation is a well known clinical characteristic of some patients with Rett syndrome, and there has been research into the causes of the prolonged apnoeic episodes and hypoxaemia that are also seen in these patients. ${ }^{4} \mathrm{~A}$ study by Glaze et al has suggested that hyperventilation is a compensatory response to periods of disorganised breathing and hypoxaemia. ${ }^{5}$ Our findings do not confirm these results, but show that hyperventilation is the primary respiratory problem and that the prolonged apnoea and hypoxaemia are secondary components. In this paper we present data on the prevalence of hyperventilation and its effects on respiratory function, heart rate, and plasma biochemistry.

\section{Patients and methods}

The control group comprised eight girls and 10 boys aged between 4 and 6 years who had been originally and randomly recruited at birth as part of a large prospective study of respiratory function, ${ }^{6}$ and four girls and one boy aged between 6 and 15 years who were recruited from schools in the Doncaster area. All were healthy and were studied at home.

Eighteen girls between 6 and 17 years with Rett syndrome were studied. The clinical characteristics of 14 of them have previously been reported by Kerr and Stephenson ${ }^{2}$; four were new cases. Because no organic marker has yet been described for Rett syndrome, it has to be distinguished on clinical 
grounds alone. To allow valid comparisons among cases from different centres we have defined precisely what we mean by 'classic Rett syndrome' and have indicated any cases in the series who do not have all the classic features. ${ }^{7}$

In this study a classic case of Rett syndrome met all the following criteria:

(1). There were no serious complications during pregnancy, birth, or the neonatal period, and the girl conformed to accepted standards for psychomotor development during the first 4 months; (2) the occipitofrontal head circumference was within or close to the normal range at birth and increased at a normal rate for at least the first four months, but suboptimal growth occurred later in childhood; (3) there was subtle evidence of slowing in psychomotor development in the first year, failure to use the hands properly after the first 12 months, and failure to develop speech beyond single utterances; (4) there was otherwise unexplained loss of skills in the use of hands and speech between the ages of nine and 30 months associated with social withdrawal and deterioration in non-verbal communication; and (5) characteristic repetitive hand movements developed, consisting of simple hand wringing or squeezing, clapping or tapping, and washing or rubbing. Following this regression, lack of postural control developed, often with involuntary movements, the use of hands deteriorated and became uncoordinated, and the child had no useful speech although non-verbal communication improved.

In addition the child had a profound and essentially static mental handicap with no other obvious cause, and was prone to sudden spells of agitated behaviour including panic, laughter, or altered respiration. There were no dysmorphic features.

Other features of Rett syndrome are cold, small, and slim hands and feet, epileptic seizures and nonepileptic absences often preceded by hyperventilation, gaseous abdominal distension, wasting, progressively increasing tone (especially in the lower limbs), progressive scoliosis, and deformity of the feet and ankles.

Only four of our 18 patients had atypical features; case 9 , aged 6 years, had a greater than usual (although still poor) ability to speak and use her hands. For the last three years she had undergone a programme of stimulation, teaching, and exercises for five hours a day, six days a week. The mother of case 10 had a history of infertility, and had had hormone treatment for a threatened abortion at 11 weeks' gestation. Polyhydramnios was present in the third trimester. In cases 15 and 18, stereotypic hand movements had virtually disappeared by the time of this study.
The control subjects underwent single long term tape recordings (awake and asleep) of oxygen saturation, arterial pulse waveforms, expired carbon dioxide, and abdominal breathing movements using the equipment described below (mean duration $9 \cdot 7$ hours, range $6-12 \cdot 5$ ).

To evaluate respiratory function in the 18 patients with Rett syndrome, recordings were made of various signals in different combinations with an FM tape recorder (Racal Store 4); these were made while subjects were awake in all cases, and overnight in 11. When more than four signals were required a single channel multiplexer (Medical Physics, Sheffield University) was used (frequency response $\mathrm{DC}$ to $30 \mathrm{~Hz} /$ channel).

Expired carbon dioxide concentrations were recorded from a constantly sampling infrared analyser (Engstrom Eliza) either from a face mask or from a mouth probe held by an observer (median total response time 2.5 seconds, sampling rate $100 \mathrm{ml}$ minute). During sleep, expired carbon dioxide was measured from just inside one of the external nares using a fine cannula taped on to the upper lip. Only expired carbon dioxide signals showing adequate plateau formation were analysed. Transcutaneous carbon dioxide measurements were recorded by an electrochemical sensor (Hewlett Packard 78834A), which was heated to $42^{\circ} \mathrm{C}$. Constants (according to the method of Hazinski and Severinghaus ${ }^{8}$ ) were applied to compensate for increased skin temperature and for skin carbon dioxide production (gain 0.79 , offset $-3 \mathrm{~mm} \mathrm{Hg}$ ). The sensor was taped on to the skin of the upper chest wall.

Beat to beat arterial oxygen saturation, ${ }^{9}$ the arterial pulse waveforms from which this was calculated, and an electrocardiogram were obtained from a modified pulse oximeter (Nellcor Respox 2). The oxygen sensor was placed on the toe and electrocardiographic electrodes in the lead II position. Breathing movements were detected in all patients with Rett syndrome using respiratory inductance plethysmography (Respitrace, Studley Data Systems), either from a vest (P K Morgan) encompassing the whole of the chest wall or from two separate bands placed at the levels of the nipples and umbilicus. In two cases abdominal breathing movements were also detected from a pressure capsule transducer (Graseby, MR10). In 10 of the 23 controls, breathing movements were recorded from a pressure capsule alone and in 13 from both pressure capsule and inductance plethysmography. Recordings of airflow integrated to volume change were obtained from a close fitting face mask and a Fleisch size 2 pneumotachograph (Spectramed). Calibration signals of $60 \mathrm{ml}$ were obtained using a purpose built syringe. 
Six channels of electroencephalography, one channel of electro-oculography, and one channel of electrocardiography were recorded onto a battery operated cassette tape recorder (Medilog 9000, Oxford Medical Systems) with pre-amplifiers on a collar placed around the neck. During daytime recordings these signals were incorporated onto a video tape and video monitor (the Quarrier's system), ${ }^{10}$ and time linkages were synchronised between the video recordings and the respiratory physiology data on the FM tape recorder. Numerical and oscilloscopic representations of the respiratory data were also recorded on video film. Tape recordings of the respiratory physiological parameters were printed out using an eight channel ink jet chart recorder (Siemens EEG 8). Standard recordings of the electrocardiogram were made on eight patients using a Cambridge VS-550 ECG recorder.

Single radial arterial 'stab' samples for blood gas analysis were taken and analysed during periods of hyperventilation in children showing abnormally reduced concentrations of transcutaneous or end tidal carbon dioxide, or both. In three such patients samples were not obtained. In one (case 8) the parents refused consent. In the second (case 3) bronchospasm was present as well as large amplitude and rapid breathing, but end tidal and transcutaneous carbon dioxide were not reduced. In the third (case 10) a sample could not be obtained during the hyperventilation. Plasma concentrations of sodium, potassium, chloride, magnesium, phosphate, ionised calcium, and lactate were also measured.

Periods of hyperventilation were diagnosed when plateau values of end tidal carbon dioxide fell below 3.0 volume $\%$, amplitude of breathing movements increased, and trancutaneous carbon dioxide fell below $30 \mathrm{~mm} \mathrm{Hg}$. The durations of all apnoeic pauses were measured in the controls the longest of which was 19 seconds. All pauses over 19 seconds occurring in the 18 patients with Rett syndrome were measured together with their effects on oxygen saturation.

Periodic apnoea was defined according to Richards $e a^{11}$ and measured in cases and controls. Thus a cycle of periodic apnoea consisted of a group of 1-19 breaths followed by an apnoeic pause of $\geqslant 4.0$ seconds. Each cycle was preceded by a similar pause or by a cycle of periodic apnoea. A minimum of two cycles of periodic apnoea was required to complete an episode of periodic apnoea.

\section{Results}

Analysis of the tape recordings from the 23 controls showed no evidence of hyperventilation. Apnoeic pauses up to 19 seconds in duration were identified

Table 1 Clinical details of patients with Rett syndrome

\begin{tabular}{|c|c|c|c|c|c|c|c|c|}
\hline Case No & $\begin{array}{l}\text { Age } \\
\text { (years) }\end{array}$ & $\begin{array}{l}\text { Occipitofrontal } \\
\text { head } \\
\text { circumference } \\
(\%)\end{array}$ & $\begin{array}{l}\text { Motor } \\
\text { seizures }\end{array}$ & Scoliosis & $\begin{array}{l}\text { Foot } \\
\text { deformity }\end{array}$ & $\begin{array}{l}\text { Gaseous } \\
\text { abdominal } \\
\text { distension }\end{array}$ & $\begin{array}{l}\text { Past } \\
\text { history } \\
\text { of } \\
\text { hyperventilation }\end{array}$ & $\begin{array}{l}\text { Current } \\
\text { treatment }\end{array}$ \\
\hline \multicolumn{9}{|l|}{ Group 1: } \\
\hline 1 & 6 & $3-10$ & Yes & Yes & Yes & No & Yes & Carbemazepine \\
\hline 2 & 12 & 3-10 & Yes & Yes & Yes & Yes & Yes & Carbemazepine \\
\hline 3 & 11 & $<3$ & No & Yes & Yes & Yes & Yes & Salbutamol : \\
\hline 4 & 10 & $<<3$ & Yes & Yes & Yes & Yes & Yes & Sodium valproate \\
\hline 5 & 7 & 10 & No & No & No & Yes & Yes & None \\
\hline 6 & 16 & $<<<3$ & No & Yes & Yes & Yes & Yes & None \\
\hline 7 & 7 & $<3$ & Yes & Yes & No & Yes & Yes & Clonazepam, carbemazepine \\
\hline 8 & 12 & $<3$ & Yes & Yes & Yes & Yes & Yes & Carbemazepine \\
\hline $9^{*}$ & 6 & $10-25$ & Yes & No & No & No & Yes & Prednisolone : \\
\hline $10^{*}$ & 6 & 3 & Yes & Yes & Yes & Yes & Yes & Carbemazepine \\
\hline \multicolumn{9}{|l|}{ Group 2: } \\
\hline 11 & 17 & 25 & Yes & No & Yes & Yes & Yes & Carbemazepine \\
\hline 12 & 14 & $<3$ & No & Yes & Yes & Yes & Yes & None \\
\hline 13 & 16 & 3 & Yes & No & Yes & Yes & Yes & Sodium valproate \\
\hline 14 & 13 & $<<3$ & Yes & Yes & Yes & Yes & Yes & Sodium valproate \\
\hline \multicolumn{9}{|l|}{ Group 3: } \\
\hline $15^{*}$ & 6 & $25-50$ & Yes & Yes & Yes & No & No & Carbemazepine \\
\hline 16 & 7 & $<3$ & Yes & Yes & Yes & Yes & No & $\begin{array}{l}\text { Sodium valproate, } \\
\text { trimeprazine tartrate }\end{array}$ \\
\hline 17 & 14 & $<<3$ & No & Yes & No & Yes & No & None \\
\hline $18^{*}$ & 6 & $<3$ & Yes & Yes & Yes & No & No & Clonazepam \\
\hline
\end{tabular}

\footnotetext{
*Atypical features present.
} 
1042 Southall, Kerr, Tirosh, Amos, Lang, and Stephenson

Table 2 Selected physiological data on 18 patients with Rett syndrome

\begin{tabular}{|c|c|c|c|c|c|c|c|c|c|}
\hline \multirow[t]{2}{*}{ Measurement } & \multicolumn{9}{|l|}{ Case No } \\
\hline & 1 & 2 & 3 & 4 & 5 & 6 & 7 & 8 & 9 \\
\hline Duration of recording (hours) & $14 \cdot 3^{*}$ & $13 \cdot 2^{*}$ & $12 \cdot 9^{*}$ & $13 \cdot 2^{*}$ & $13 \cdot 8^{*}$ & $11 \cdot 5^{*}$ & $14 \cdot 7^{*}$ & 0.9 & $16 \cdot 9^{*}$ \\
\hline \multicolumn{10}{|l|}{$\begin{array}{l}\text { Lowest values when awake: } \\
\text { Transcutaneous carbon }\end{array}$} \\
\hline dioxide $(\mathrm{mm} \mathrm{Hg})$ & 24 & 26 & 32 & 18 & 13 & 20 & 8 & 21 & 18 \\
\hline End tidal carbon dioxide (volume \%) & $2 \cdot 2$ & $2 \cdot 2$ & $4 \cdot 2$ & 2.1 & $1 \cdot 4$ & $2 \cdot 0$ & $1 \cdot 6$ & $2 \cdot 4$ & $1 \cdot 8$ \\
\hline \multicolumn{10}{|l|}{ Average values when asleep: } \\
\hline \multicolumn{10}{|l|}{ Transcutaneous carbon } \\
\hline dioxide $(\mathrm{mm} \mathrm{Hg})$ & 52 & 59 & 53 & NR & 37 & 32 & 38 & NR & 51 \\
\hline End tidal carbon dioxide (volume \%) & $5 \cdot 4$ & $7 \cdot 2$ & $4 \cdot 6$ & 5.8 & $4 \cdot 2$ & $4 \cdot 0$ & $4 \cdot 8$ & NR & $4 \cdot 8$ \\
\hline Longest apnoeic pause when awake & 49 & 98 & 27 & 125 & 74 & 43 & 34 & 24 & 60 \\
\hline \multicolumn{10}{|l|}{ Lowest oxygen saturation when awake (\%) } \\
\hline (below $50 \%$ oximeter inaccurate) & 60 & $<50$ & 92 & $<50$ & $<50$ & 66 & 70 & 92 & $<50$ \\
\hline Valsalva manoeuvres & Yes & Yes & Yes & Yes & Yes & Yes & Yes & Yes & Yes \\
\hline \multicolumn{10}{|l|}{ Periodic apnoea* (asleep) } \\
\hline (minutes/hour) & $13 \cdot 5$ & $17 \cdot 8$ & $11 \cdot 3$ & 5.6 & $1 \cdot 7$ & $13 \cdot 8$ & $17 \cdot 0$ & $56 \cdot 1$ & $1 \cdot 7$ \\
\hline QTc (second) & 0.44 & 0.40 & NR & 0.45 & 0.41 & 0.42 & 0.45 & NR & 0.43 \\
\hline
\end{tabular}

*Both day and overnight recordings; $\mathrm{NR}=$ not recorded.

Table 3 Selected biochemical data on eight of 18 patients with Rett syndrome

\begin{tabular}{|c|c|c|c|c|c|c|c|c|c|}
\hline \multirow[t]{2}{*}{ Measurement } & \multicolumn{8}{|c|}{ Case No } & \multirow[t]{2}{*}{ Normal range } \\
\hline & 1 & 2 & 4 & 5 & 6 & 7 & 9 & 10 & \\
\hline \multicolumn{10}{|l|}{ Plasma concentrations $(\mathrm{mmol} / \mathrm{l})$ : } \\
\hline Chloride & 109 & 110 & NS & 110 & 109 & 110 & 105 & NS & $92-109$ \\
\hline Ionised calcium & $1 \cdot 13$ & $1 \cdot 25$ & 0.67 & NM & $1 \cdot 24$ & $1 \cdot 26$ & $1 \cdot 24$ & $1 \cdot 19$ & $1 \cdot 19-1 \cdot 31$ \\
\hline Phosphate & $1 \cdot 6$ & $1 \cdot 6$ & $1 \cdot 7$ & 1.4 & $1 \cdot 5$ & $1 \cdot 6$ & 1.9 & $1 \cdot 8$ & $0.7-1.4$ \\
\hline Lactate & $2 \cdot 1$ & $1 \cdot 4$ & $2 \cdot 5$ & 3.4 & $1 \cdot 1$ & $2 \cdot 0$ & $2 \cdot 2$ & $1 \cdot 8$ & $0.7-1.8$ \\
\hline \multicolumn{10}{|l|}{${ }^{*}$ Arterial: } \\
\hline $\mathrm{pH}$ & $7 \cdot 48$ & $7 \cdot 51$ & $7 \cdot 60$ & $7 \cdot 59$ & $7 \cdot 47$ & $7 \cdot 49$ & $7 \cdot 55$ & NS & $7 \cdot 35-7 \cdot 45$ \\
\hline Bicarbonate (mmol/1) & 17 & 22 & 15 & 13 & 18 & 20 & 21 & NS & $22-26$ \\
\hline Carbon dioxide (mm $\mathrm{Hg}$ ) & 30 & 24 & 16 & 13 & 25 & 23 & 22 & NS & $35-45 \mathrm{~mm} \mathrm{Hg}$ \\
\hline Base excess & $-1 \cdot 0$ & -0.9 & $-1 \cdot 5$ & $-4 \cdot 1$ & $-2 \cdot 8$ & $-2 \cdot 4$ & 0.5 & NS & $-2.0-+2.0 \mathrm{mmol} / \mathrm{l}$ \\
\hline
\end{tabular}

*Samples taken during hyperventilation; NS=not sampled; plasma concentrations of potassium, sodium, and magnesium were all normal.

(range of longest pause/recording 8-19 seconds, median 14) but these pauses were not accompanied by Valsalva manoeuvres. ${ }^{12}$

The patients were divided into three groups according to the results of their recordings and the clinical histories (table 1).

GROUP 1 (CASES 1-10)

There were 10 patients in group 1 , with an average age of 9.3 years. When awake they all had long periods of hyperventilation. Table 2 shows the severity of their hypocapnia with transcutaneous carbon dioxide values reduced to $8 \mathrm{~mm} \mathrm{Hg}$ and end tidal carbon dioxide values reduced to 1.4 volume \% (control values 4.6 to 5.3 volume \%). All seven of those from whom arterial blood samples were taken had respiratory alkalaemia (highest $\mathrm{pH} 7 \cdot 60$, table 3 ). When asleep none of the 10 patients had hyper- ventilation (end tidal carbon dioxide values were 4.0 to $7 \cdot 2$ volume $\%$, control values $5 \cdot 2$ to 6.4 volume \%) (table 2, fig 1).

During periods of hyperventilation the children seemed agitated with increased hand movements, dilated pupils, increased heart rates, rocking body movements, and increased muscle tone. They breathed through wide open mouths, ribcage excursions were greater than abdominal excursions, and accessory muscles of respiration were used. In some hyperventilation occurred almost continuously while they were awake, and in others it was interrupted by periods of normal breathing. During these latter periods the children remained awake but slightly drowsy. In some cases hyperventilation was clinically obvious. In others (for example case 4) it was only indicated by end tidal and transcutaneous carbon dioxide measurements. Though case 3 had 
Table 2 Continued

\begin{tabular}{|c|c|c|c|c|c|c|c|c|c|}
\hline & & & & & & & & & Range in 18 controls \\
\hline 10 & 11 & 12 & 13 & 14 & 15 & 16 & 17 & 18 & \\
\hline $17 \cdot 1^{*}$ & $10 \cdot 4^{*}$ & 0.6 & $0 \cdot 5$ & 0.4 & $14 \cdot 7^{*}$ & $1 \cdot 5$ & 0.4 & 0.5 & $6 \cdot 0$ to $12 \cdot 5$ \\
\hline 13 & NR & 42 & 36 & 51 & 44 & 46 & 38 & 37 & NR \\
\hline $2 \cdot 0$ & $3 \cdot 8$ & $3 \cdot 8$ & $4 \cdot 2$ & $4 \cdot 4$ & $4 \cdot 5$ & $4 \cdot 4$ & $4 \cdot 8$ & $4 \cdot 0$ & $4 \cdot 6$ to $5 \cdot 3$ \\
\hline 42 & NR & NR & NR & NR & 51 & NR & NR & NR & NR \\
\hline $5 \cdot 3$ & 6.4 & NR & NR & NR & $6 \cdot 2$ & NR & NR & NR & 5.2 to 6.4 \\
\hline 27 & 84 & 24 & 21 & 9 & 11 & 11 & 11 & 16 & $19^{*}$ \\
\hline$<50$ & 80 & 98 & 95 & 98 & 94 & 97 & 98 & 98 & 96 \\
\hline Yes & Yes & Yes & Yes & Yes & Yes & Yes & No & Yes & None \\
\hline $9 \cdot 1$ & $11 \cdot 3$ & $17 \cdot 8$ & 0 & $35 \cdot 2$ & $4 \cdot 5$ & $2 \cdot 0$ & $2 \cdot 5$ & $4 \cdot 4$ & 0 to 0.75 \\
\hline 0.43 & NR & NR & NR & NR & NR & NR & NR & NR & NR \\
\hline
\end{tabular}

increased ventilatory excursions, she did not achieve the same degree of hypocapnia as the other patients. She had bronchospasm during the recording, having suffered bronchial asthma for the previous two years.

Periods of hyperventilation were often interrupted by pauses in inspiratory efforts, some of them prolonged ( $\geqslant 20$ seconds) (table 2 , fig 2 , and fig 3). These prolonged pauses were not induced by seizure activity as shown by surface electroencephalography recordings (fig 3) except on one occasion (case 9). Most of these pauses contained a Valsalva manoeuvre ${ }^{12}$ during which the large inspiratory airflow associated with hyperventilation was followed at the end of inspiration by active expiratory muscle activity but no expiratory flow.

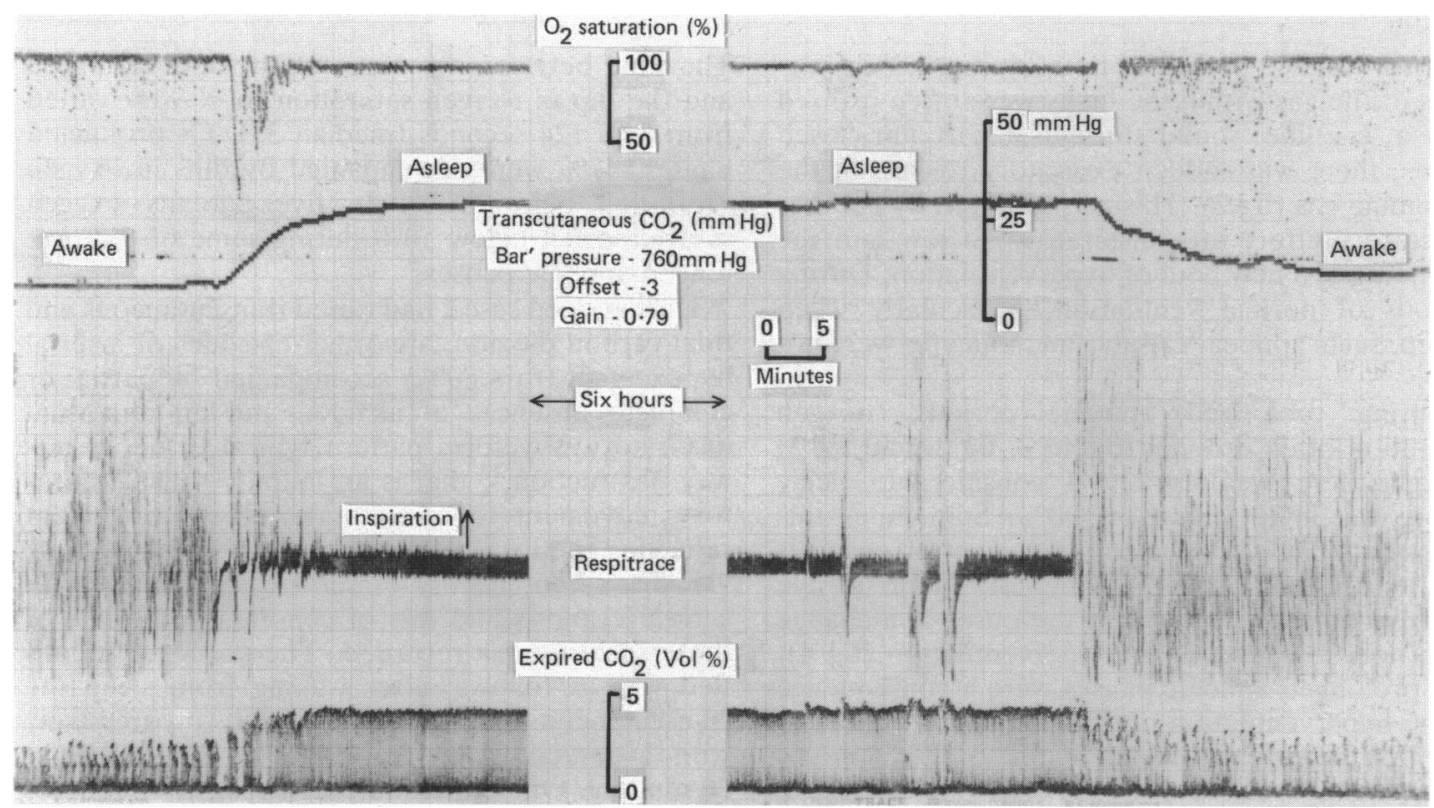

Fig 1 Interrupted printout of an overnight tape recording (case 5) showing transition from awake to asleep and back again. During the awake periods before and after sleep there is hyperventilation with a transcutaneous carbon dioxide down to $8 \mathrm{~mm} \mathrm{Hg}$. During sleep the transcutaneous carbon dioxide and end tidal carbon dioxide are normal. 


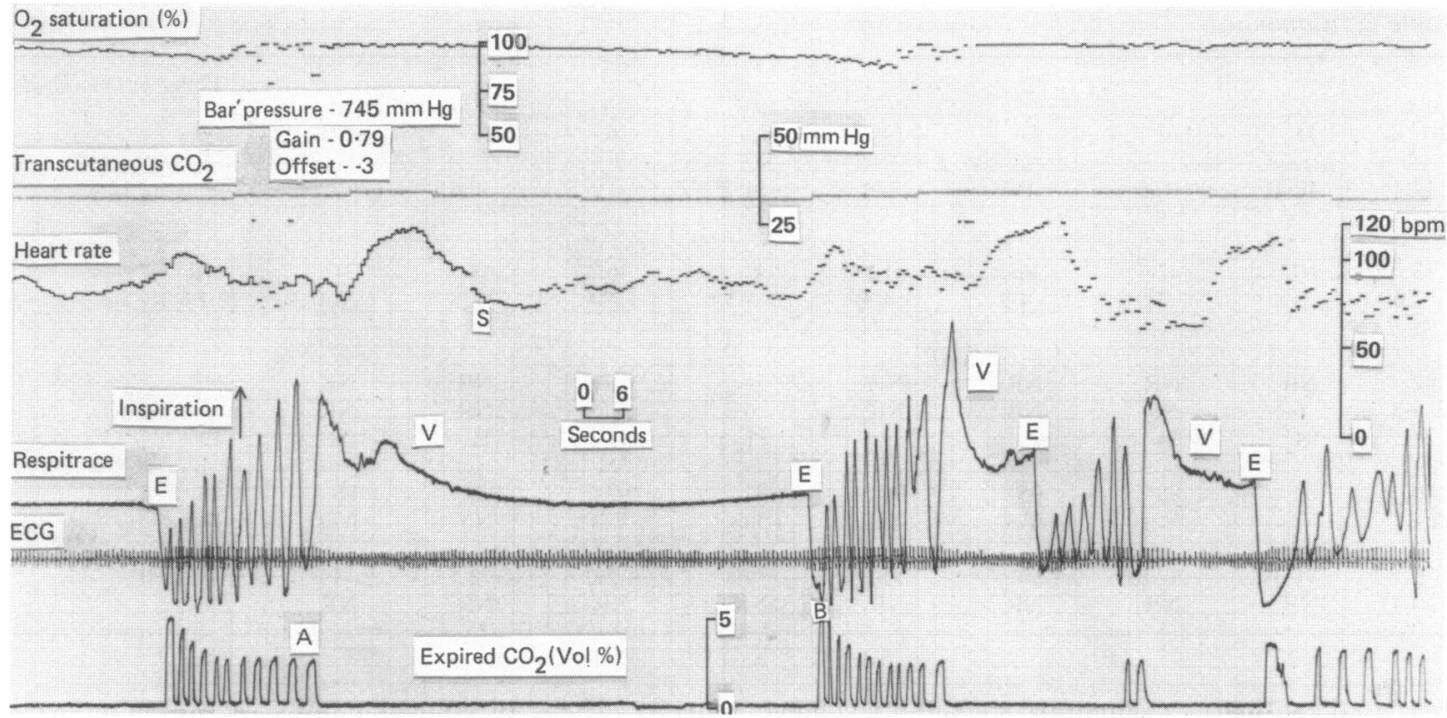

Fig 2 Section of recording when awake (case 2). Four episodes of apnoea each associated with Valsalva manoeuvre $(V)$ are shown, the longest reading 77 seconds (from $A$ to $B$ ) during which there is a small fall in oxygen saturation (to $90 \%)$. Preceding each pause the end tidal carbon dioxide is reduced by a period of hyperventilation to about 2.4 volume $\%$. After the prolonged pause $(A B)$ the end tidal carbon dioxide reaches 5.0 volume \%. Throughout recording the transcutaneous carbon dioxide is about $32 \mathrm{~mm} \mathrm{Hg}$. Each apnoeic episode begins at end of inspiration. Lung volume is maintained (by Valsalva manoeuvres) until positions $E$ where there is sudden expiration of gas and the immediate onset of hyperventilation. During periods of hyperventilation and the early part of the apnoeic pause (Valsalva manoeuvre) there is a comparative bradycardia. Increase in heart rate begins within six seconds of onset of the pause. About 26 seconds (position $S$ ) into the prolonged apnoeic episode $(A B)$ the heart rate slows again.

After a variable period of time, during which portions of the gas within the lungs were often expired with a 'cry like' sound through a partially closed glottis, there was sudden expiratory release of the remaining gas (fig 2). This was followed by another inspiratory effort with inspiratory airflow and the beginning of a new bout of hyperventilation. During periods of normal ventilation, particularly when asleep, such 'apnoea/Valsalva' manouevres were not seen.

During prolonged apnoeic periods, oxygen saturation often dropped (table 2, fig 2, and fig 3) though there was usually a considerable delay before the level fell below $90 \%$. Sometimes this hypoxaemia was associated with central cyanosis and a transient lack of awareness. None of the children were hypoxaemic at the onset of a change from normal breathing to hyperventilation (fig 4). The prolonged apnoeic pauses were a consequence of the hyperventilation not the reverse.

All 10 patients with hyperventilation had apnoeic pauses of $\geqslant 20$ seconds (table 2). Their median duration was 35 seconds and the longest was 125 seconds. The number of these prolonged pauses varied from $0 \cdot 12$ to $11.64 \mathrm{p} /$ hour of recording, median 1.96 /hour.
The time between the onset of the apnoeic pause and the dip in oxygen saturation to $<90 \%$ varied from 8 to 124 seconds (median 33). Of prolonged pauses, $47 \%$ were accompanied by dips in oxygen saturation below $90 \%$. In five patients oxygen saturation fell below $50 \%$ during some of the prolonged apnoeic pauses.

During sleep case 2 had raised transcutaneous end tidal carbon dioxide, abnormal episodes of arterial hypoxaemia (to $<80 \%$ ) accompanied by partial or complete absences of airflow, and an abnormal inspiratory waveform pattern typical of upper airway obstruction, ${ }^{13}$ that is an initially rapid inspiratory movement followed by a slower movement reflecting the increased inspiratory resistance. Case 9 had a recent history of seizures associated with central cyanosis and loss of consciousness. One of these seizures was recorded. The sequence identified was as follows: after waking from sleep the transcutaneous carbon dioxide fell progressively with hyperventilation from $50 \mathrm{~mm} \mathrm{Hg}$ to about $26 \mathrm{~mm} \mathrm{Hg}$. One particular episode of hyperventilation was associated with the development of seizure discharge on the electroencephalogram. The onset of this seizure coincided with pallor, dilation of 


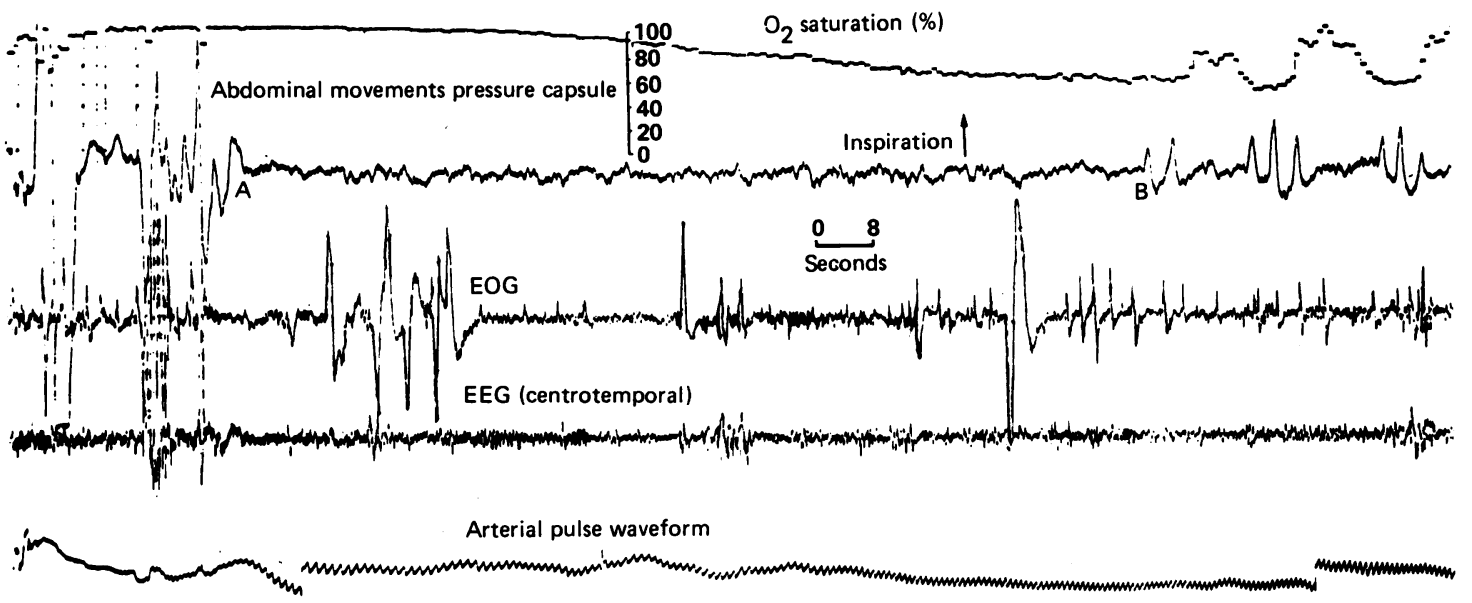

Fig 3 Prolonged apnoeic pause (A-B) of 125 seconds (case 4). The electro-oculogram and electroencephalogram recordings show that the child was awake and there was no evidence of an associated seizure.

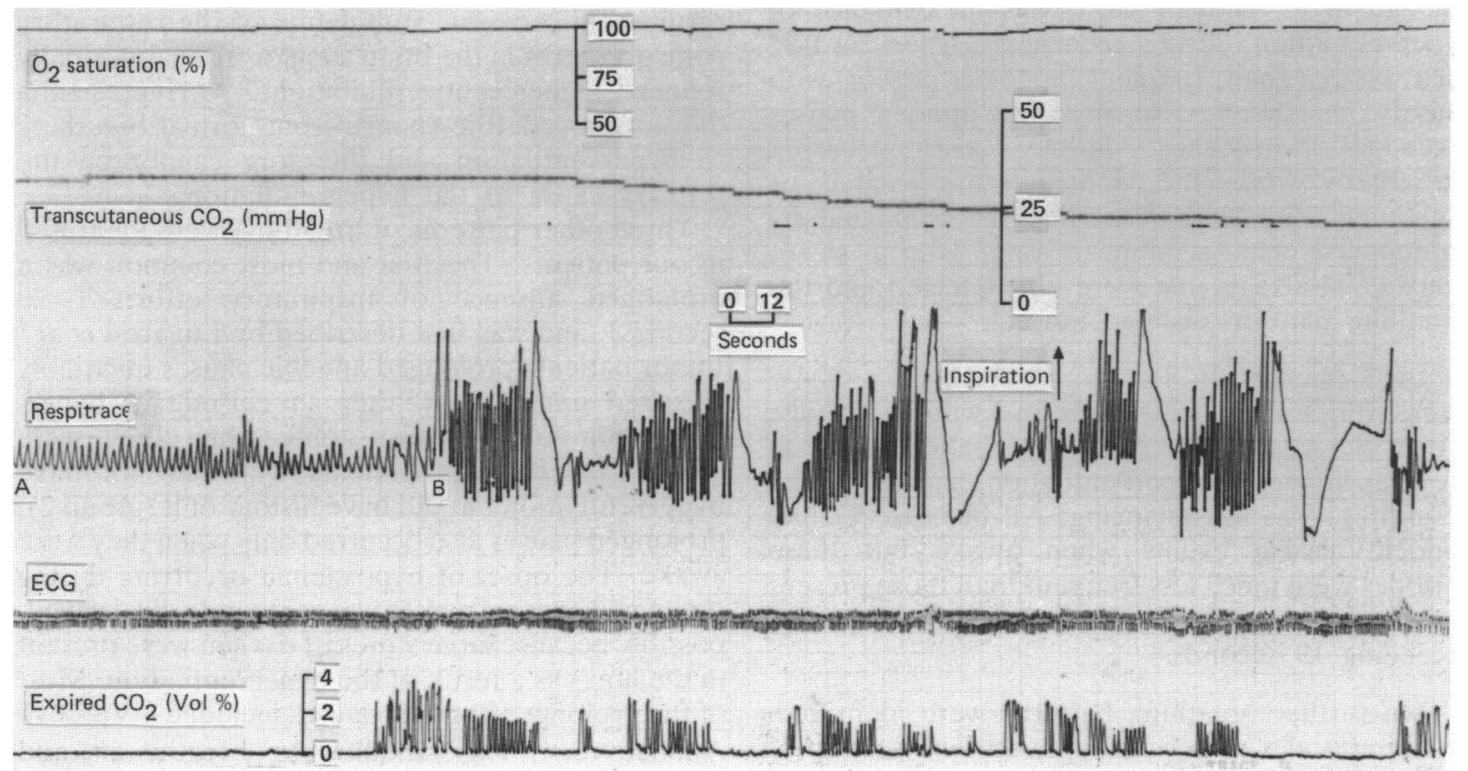

Fig 4 Section of daytime recording (case 5). An episode of breathing without hyperventilation (A to $B$ ) is followed by periods of hyperventilation (as shown by end tidal carbon dioxide and the increased amplitude and frequency of the breathing movements) and apnoeic pauses. Hyperventilation episodes are accompanied by a progressive fall in trancutaneous carbon dioxide. There is no evidence of hypoxaemia preceding the onset of hyperventilation (oxygen saturation $98-100 \%$ ).

pupils, and a blank facial expression. The child sat erect, then fell back with grey twitching lips and appeared to lose consciousness. Clutching movements of the hands and jerking of the trunk preceded recovery. At the time of onset of the seizure there was prolonged inhibition of inspiratory efforts (without a Valsalva manoeuvre) for the dura- tion of the seizure (about 59 seconds). Hypoxaemia developed during this prolonged apnoea and became severe (oxygen saturation $<50 \%$ ). As the seizure discharge on the electroencephalogram became less intense, a large inspiratory effort occurred producing gradual recovery from the hypoxaemia. ${ }^{14}$ 
In cases 1,4 , and 7, QT intervals (corrected for heart rate using Bazett's formula) were at the upper limit of normal during periods of hyperventilation (table 2) (normal range mean (SD) $0.404(0.026)$ seconds $\left.{ }^{15}\right)$.

All seven patients who had blood samples taken during hyperventilation (table 3 ) showed respiratory alkalaemia, plasma chloride concentrations at the upper limit of normal, and reduced plasma bicarbonate concentrations. Ionised calcium concentrations were in the lower normal range and plasma lactate concentrations were in the upper normal range.

GROUP 2 (CASES 11-14)

There were four patients in group 2 with an average age of 15.0 years; they were older than those in group 1 (table 1). All four gave histories suggestive of hyperventilation in earlier childhood, and in case 11 respiratory alkalaemia had been documented at the age of 6 . Though there was no evidence of hyperventilation during recordings when awake, each patient had frequent apnoeic pauses with Valsalva manoeuvres. In three, the apnoeic pauses exceeded 19 seconds. These pauses occurred particularly when the child became excited or frightened, and were sometimes accompanied by pronounced changes in heart rate. During sleep, apnoea/Valsalva events were not detected and the breathing patterns seemed normal.

GROUP 3 (CASES 15-18)

There were four patients in group 3 with an average age of 8.3 years. Three of these patients had no previous history of hyperventilation, and in one the description was unconvincing. All but case 17 had apnoea/Valsalva events when awake but these episodes were much less frequent than those present in patterns in group 2. None had apnoeic pauses exceeding 19 seconds.

Two further breathing patterns were identified: firstly, episodes of periodic apnoea were seen in 15 of the $23(65 \%)$ controls (durations 0.05 to 0.75 minutes/hour of recording: median duration of those with periodic apnoea $0 \cdot 13$ minutes/hour). Only one of the 18 patients with Rett syndrome (case 13) had no periodic apnoea. All the remaining patients had larger quantities than the controls (1.7 to $56 \cdot 1$ minutes/hour: median 11.3 minutes/hour). Cases 1-10 with hyperventilation had values for periodic apnoea varying from 1.7 to 56.1 (median 12.4 ) minutes/hour. Cases 11-14 who had past histories of hyperventilation, had values for periodic apnoea varying from 0 to 35.2 (median 14.5) minutes/hour. The values of periodic apnoea for cases $15-18$ varied from 2.0 to 4.5 (median 3.4 minutes/hour).
The second pattern was exemplified by case 10 who had brief episodes of hypoxaemia during which breathing movements and airflow continued. None of these episodes included the abnormal inspiratory waveforms typical of upper airway obstruction documented in case 2; this pattern of breathing and hypoxaemia was not found in the controls.

\section{Discussion}

Abnormal hyperventilation, with consequent hypocapneic alkalaemia present only during active wakefulness, was the major respiratory abnormality that we found in this group of children with Rett syndrome. We found hyperventilation in $56 \%$ of patients, and in an additional $22 \%$ (generally older children) there was a history suggesting it. We do not have an adequate explanation for the hyperventilation of Rett syndrome. Because it does not occur during sleep we speculate that it is likely to result from excessive stimulation of the respiratory control centres in the brain stem or from abnormally reduced higher centre inhibition. ${ }^{16-18}$ Hypoxaemia did not precede the change from normal breathing to hyperventilation and therefore cannot be the primary cause of the hyperventilation.

Three other patterns of breathing were identified in our patients. The first and most common was a prolonged absence of inspiratory efforts $(\geqslant 20$ seconds), and was first described by Lugaresi et al. ${ }^{4}$ In our patients prolonged apnoeic pauses invariably occurred immediately after an episode of hyperventilation and therefore only when they were awake. In the four patients who did not have hyperventilation but did have history of it (group 2), prolonged pauses also occurred only when they were awake. The onset of hypoxaemia occurring during prolonged apnoeic pauses was comparatively delayed, possibly because large stores of oxygen were present in the lungs as a result of the hyperventilation. Most of the prolonged apnoeic pauses included a Valsalva manoeuvre. ${ }^{12}$ The stimulus to breathe in and terminate the prolonged apnoea was probably associated with an increase in carbon dioxide, and sometimes with hypoxaemia. Hyperventilation in healthy human adult subjects does not result in a prolonged absence of inspiratory efforts; this response has been described only when there was diffuse disease of the forebrain, ${ }^{16}$ or when the subject was anaesthetised or heavily sedated. ${ }^{17}$ In case 9 a clinical seizure occurred during hyperventilation and was associated with a prolonged absence of inspiratory efforts.

The second pattern, periodic apnoea, ${ }^{11}$ occurred in both patients and controls. In all but one of the patients with Rett syndrome, values exceeded those 
in the control group (table 2) by ratios of 2:1 to 75:1. Increases were particularly noticeable in patients with hyperventilation or with a history of hyperventilation. Some of these increases in periodic apnoea undoubtedly reflected the apnoea/Valsalva manoeuvres that frequently occurred in succession. Sometimes the intervening episodes of apnoea were associated with hypoxaemia. Cheyne-Stokes breathing (a form of periodic apnoea) has previously been described in association with hyperventilation by Brown and Plum. ${ }^{19}$

The third pattern, that of continued inspiratory efforts and inspiratory airflow but with accompanying hypoxaemia, was found in one patient (case 10). There was no evidence of partial upper airway obstruction, and these findings could suggest the presence of a mismatch in ventilation/perfusion associations (possibly through areas of alveolar atelectasis) ${ }^{20} \mathrm{It}$ is possible that in this patient hyperventilation had impaired the function of lung surfactant. $^{21}$

Our findings that respiratory abnormalities in patients with Rett syndrome are present only when they are awake confirm those of Glaze $e t a f$; we do not, however, agree with these authors that the hyperventilation is compensating for periods of disorganised breathing and hypoxaemia. Our recordings clearly show that hyperventilation is the primary problem and that its onset does not occur in response to hypoxaemia, rather, hypoxaemia is a consequence of the prolonged apnoeic episodes induced by the hyperventilation. Unlike Glaze $e t a l^{5}$ we found that breath holding and Valsalva manoeuvres occurred often in 14 of our 18 patients. Their finding that end tidal carbon dioxide was normal during disorganised breathing does not concur with our results. The lack of a plateau on the expired carbon dioxide trace shown in their figure could be one reason for their failure to identify the low end tidal carbon dioxide values indicative of hyperventilation.

There are interesting parallels between some of the characteristic features of Rett syndrome that we have described and the hyperventilation syndrome that is documented in children and adults in which the following signs have been reported: peripheral vasoconstriction, ${ }^{22-24}$ neuromuscular irritability leading to tetany and muscle contractures, ${ }^{25}$ parasthesiae and a lowered pain threshold ${ }^{26}$; and the induction of seizures. ${ }^{27}$

There are also biochemical parallels between the hyperventilation syndrome and Rett syndrome. Respiratory alkalaemia (a consequence of hyperventilation) produces a compensatory reduction in plasma bicarbonate ions. ${ }^{23-24}$ This is accomplished by an increase in renal excretion and a correspond- ing retention of ammonium ions, and by influx of bicarbonate ions into the cells in exchange for chloride ions. These compensatory mechanisms may result in a decrease in plasma bicarbonate and an increase in plasma chloride and ammonia concentrations. Alkalaemia may also increase the concentrations of lactate and pyruvate in plasma and cerebrospinal fluid. ${ }^{28}$ These biochemical findings, sometimes unconfirmed, have been reported in Rett syndrome. ${ }^{129} 30$ Increased plasma chloride concentrations, decreased plasma bicarbonate concentrations, and lactate concentrations at the upper limit of normal were identified during hyperventilation in our patients (table 3 ).

Hyperventilation produces not only vasoconstriction in the skin but, of more importance, in the cerebral circulation. ${ }^{27}$ Moreover, alkalaemia induces a leftward shift in the oxygen dissociation curve, and theoretically may impair the unloading of oxygen to the cerebral tissues. In combination with the extracellular alkalaemia ${ }^{28}$ these effects may also increase cerebral lactic acid concentrations. The abrupt and extreme changes in cerebral blood flow that accompany sudden changes in carbon dioxide concentrations between being awake and being asleep may adversely affect cerebral perfusion. Together with the hypoxaemia accompanying abnormal apnoeic episodes, these mechanisms may contribute to the development of the cerebral impairment that has been reported in Rett syndrome. ${ }^{31} 32$ Further studies of changes in cerebral blood flow in children with Rett syndrome and hyperventilation are indicated.

Sudden unexpected death has been reported in Rett syndrome. ${ }^{33}$ Two of the 19 children referred to in our original papers of 1985 and $1986^{2}{ }^{3}$ have since died suddenly and unexpectedly aged 11 and 16 years. The known effects of disturbances of $\mathrm{pH}$ and ionised calcium on cardiac muscle excitability, ${ }^{22-24}$ and the propensity of hypocapnia to reduce coronary artery perfusion ${ }^{34}$ may be important in some cases. ${ }^{35}$ One further danger was seen in case 9 in which hyperventilation seems to have led to inhibition of inspiratory drive induced by seizure and resulting in prolonged and severe hypoxaemia.

Because severe and persistent hyperventilation could contribute to deterioration of central and peripheral neurological function in Rett syndrome it seems wise to detect and treat this component of the syndrome early in life. Monitoring of end tidal/ transcutaneous carbon dioxide can be done by noninvasive and comparatively straightforward techniques that could be applied to infants or young children presenting with developmental delay of unknown cause. Clinical observations alone are unreliable in the diagnosis of hyperventilation; this 
difficulty has been well described in adults with the hyperventilation syndrome where only occasional breaths of large tidal volume may be needed to maintain severe hypocapnia. ${ }^{36}$

In conclusion, hyperventilation is an important feature of Rett syndrome and its respiratory, neurophysiological, biochemical, and vascular consequences may contribute to the characteristic features of the syndrome. Further studies are required to determine whether correcting the hyperventilation will benefit patients with Rett syndrome. Hyperventilation appears to be the cause rather than the result of hypoxaemia.

Dr Southall was funded by Nellcor and Dr Tirosh by the British Council. The project was funded by the National Heart and Chest Hospitals, Nellcor, the Scottish Society for the Mentally Handicapped, the UK Rett Syndrome Association (Scotland), and Oxford Medical Systems. We thank the staff of the Quarriers' Homes, Corning Medical, Dr A Etchells, Mr T Holmes, Mr A Irwin, Dr A Hutchinson, and Dr F Dryburgh and their staff for their invaluable help, the parents and children who gave up so much of their free time to participate in this study, and the UK Rett Syndrome Association (Scotland) for valuable practical help.

\section{References}

${ }^{1}$ Rett A. Uber ein elgenartiges hirnatrophisches syndrom bei Hyperammonamie in Kindesalter. Wein Med Wochenschr 1966;116:723-6.

2 Kerr AM, Stephenson JBP. Rett syndrome in the west of Scotland. Br Med J 1985;291:579-82.

${ }^{3}$ Kerr AM, Stephenson JBP. A study of the natural history of Rett syndrome in 23 girls. Am J Med Genet 1986;24:77-83.

${ }^{4}$ Lugaresi E, Cirignotta F, Montagna P. Abnormal breathing in the Rett syndrome. Brain Dev 1985;7:329-33.

5 Glaze DG, Frost JD Jr, Zoghbi HY, Percy AK. Rett syndrome: characterization of respiratory patterns and sleep. Ann Neurol 1987;21:377-82.

${ }^{6}$ Southall DP, Richards JM, de Swiet M, et al.Identification of infants destined to die unexpectedly during infancy: evaluation of predictive importance of prolonged apnoea and disorders of cardiac rhythm or conduction. Br Med J 1983;286:1092-6.

${ }^{7}$ Kerr AM. Report on the Rett syndrome workshop: Glasgow, Scotland 24-25th May 1986. J Ment Defic Res 1987;31:93-113.

${ }^{8}$ Hazinski TA, Severinghaus JW. Transcutaneous analysis of arterial $\mathrm{pCO}_{2}$. Med Instrum 1982;16:150-3.

9 Southall DP, Bignall S, Stebbens VA, Alexander JR, Rivers RPA, Lissauer T. The clinical reliability of pulse oximeter and transcutaneous $\mathrm{PO}_{2}$ measurements in neonatal and paediatric intensive care. Arch Dis Child 1987;62:882-8.

${ }^{10}$ Kerr AM, Amos PM, Etchells AH, Irwin AWM, Holmes T, Stephenson JBP. A low cost method for simultaneous video recording of ambulant subject and electroencephalograph: the Quarrier's system. J Ment Defic Res (in press).

11 Richards JM, Alexander JR, Shinebourne EA, de Swiet M, Wilson AJ, Southall DP. Sequential 22 hour profiles of breathing patterns and heart rate in 110 full-term infants during their first 6 months of life. Pediatrics 1984;74:763-77.

12 Levin AB. A simple test of cardiac function based upon the heart rate changes induced by the Valsalva manoeuvre. Am J Cardiol 1966;18:90-9.

13 Southall DP, Stebbens VA, Mirza R, Lang MH, Croft CB, Shinebourne EA. Upper airway obstruction with hypoxaemia and sleep disruption in Down's syndrome. Dev Med Child Neurol 1987;29:734-42.

14 Southall DP, Stebbens VA, Abraham N, Abraham L. Prolonged apnoea with severe hypoxaemia resulting from complex partial seizures. Dev Med Child Neurol 1987;29:784-9.

15 Alimurung MM, Joseph LG, Craige E, Massell BF. The Q-T interval in normal infants and children. Circulation 1950;1: 1329-37.

${ }^{16}$ Plum F, Brown HW, Snoep E. Neurologic significance of posthyperventilation apneoa. JAMA 1962;181:1050-5.

17 Fink BR. Influence of cerebral activity in wake-fulness on regulation of breathing. J Appl Physiol 1961;16:15-20.

18 Plum F. Neurological integration of behavioural and metabolic control of breathing. In: Porter R, ed. Breathing: Hering-Breuer centenary symposium. London: Churchill Livingstone, 1970:159-75.

19 Brown HW, Plum F. The neurologic basis of Cheyne-Stokes respiration. Am J Med 1961;30:849-60.

${ }^{20}$ Southall DP, Talbert DG. Sudden alveolar atelectasis braking syndrome (SAABS). In: Hollinger MA, ed. Current topics in pulmonary pharmacology. New York: Elsevier, 1987:210-81.

21 Wyszogrodski I, Kyei-Aboagye K, Taeusch HW, Avery ME. Surfactant inactivation by hyperventilation: conservation by end-respiratory pressure. J Appl Physiol 1975;38:461-6.

22 Saltzman HA, Heyman A, Sieker HO. Correlation of clinical and physiologic manifestations of sustained hyperventilation. $N$ Engl J Med 1963;268:1431-6.

${ }^{23}$ Missri JC, Alexander S. Hyperventilation syndrome. A brief review. JAMA 1978;240:2093-6.

24 Brashear RE. Hyperventilation syndrome. Lung 1983;161: 257-73.

${ }^{25}$ Edmondson JW, Brashear RE, Li TK. Tetany: quantitative inter-relationships between calcium and alkalosis. Am J Physiol 1975;228:1082-6.

26 Iwata BA, Pace GM, Willis KD, Gamache TB, Hyman SL. Operant studies of self-injurious hand biting in the Rett syndrome. Am J Med Genet 1986;24:157-66.

${ }^{27}$ Gotoh F, Meyer JS, Takagi Y. Cerebral effects of hyperventilation in man. Arch Neurol 1965;12:410-23.

28 Plum F, Posner JB. Blood and cerebrospinal fluid lactate during hyperventilation. Am J Physiol 1967;212:864-70.

29 Haas RH, Rice MA, Trauner DA, Merritt TA. Therapeutic effects of a ketogenic diet in Rett syndrome. Am J Med Genet 1986;24:225-46.

30 Rett A. Cerebral atrophy associated with hyperammonaemia. In: Vinken PJ, Bruyn GW, eds. Handbook of Clinical Neurology Vol 29. Amsterdam: 1977:305-29.

31 Rolando S. Rett Syndrome: report of eight cases. Brain Dev 1985;7:290-6.

${ }^{32}$ Nomura Y, Segawa M, Hasegawa M. Rett syndrome-clinical studies and pathophysiological consideration. Brain Dev 1984;6:475-86.

${ }^{33}$ Harding BN, Tudway AJC, Wilson J. Neuropathological studies in a child showing some features of the Rett syndrome. Brain Dev 1985;7:342-4.

${ }^{34}$ Freeman LJ, Nixon PGF. Are coronary artery spasm and progressive damage to the heart associated with the hyperventilation syndrome? Br Med J 1985;291:851-2.

${ }^{35}$ Bouras N, Kartsounis LD, Bridges PK. Death associated with hyperventilation. Lancet 1987;i:635.

${ }^{36}$ Magarian GJ. Hyperventilation syndromes: Infrequently recognised common expressions of anxiety and stress. Medicine 1982;61:219-36.

Correspondence about respiratory physiology to Dr DP Southall, Cardiothoracic Institute, Fulham Road, London SW3 6HP, and about other aspects of Rett syndrome to Dr AM Kerr, Fraser of Allander Unit, Royal Hospital for Sick Children, Glasgow G3 SJ.

Accepted 15 February 1988 